Research Article, Issue 1
Analytical Methods in Environmental Chemistry Journal
AMECJ

\title{
Spectrofluorometric determination of L-tryptophan after preconcentration using multi-walled carbon nanotubes
}

\author{
Ehsan Zolfonoun ${ }^{a, *}$ \\ ${ }^{a}$ Material and Nuclear Fuel Research school, Nuclear Science and Technology Research Institute, Tehran, Iran
}

\section{A R T I C L E I N F O:}

Received 10 Jan 2019

Revised form $3 \mathrm{Feb} 2019$

Accepted 23 Feb 2019

Available online 19 Mar 2019

Keywords:

L-tryptophan

solid-phase extraction

multi-walled carbon nanotubes

Bioanalysis

spectrofluorometry

\begin{abstract}
A B S T R A C T
A solid-phase extraction method based on multi-walled carbon nanotubes (MWCNTs) was applied for the preconcentration of L-tryptophan ( $\alpha$-amino acid) prior to its spectrofluorometric determination. Due to the high surface area of MWCNTs, satisfactory concentration factor and extraction recovery can be achieved with only $10 \mathrm{mg}$ MWCNTs in $5 \mathrm{~min}$. The effects of $\mathrm{pH}$, sorbent amount, eluent type and time on the recovery of the analyte were investigated. Under the optimum conditions, the detection limit for L-tryptophan was $8.9 \mathrm{ng} \mathrm{mL}^{-1}$. The precision of the method, evaluated as the relative standard deviation obtained by analyzing of 10 replicates, was $2.6 \%$. The practical applicability of the developed method was examined using wheat and barley samples.
\end{abstract}

\section{Introduction}

Analysis of amino acids is important in several fields of research, particularly in food, soil, biotechnology and pharmaceutical industries $[1,2]$. Tryptophan (2-Amino-3-(1H-indol-3-yl) propanoic acid) (Trp) is an essential amino acid for humans and is required for the biosynthesis of proteins and also is important in nitrogen balance in adults. This amino acid cannot be synthesized in the human body and must be obtained from food or supplements. Tryptophan is sometimes added

\footnotetext{
* Corresponding author: Email: ezolfonoun@aeoi.org.ir DOI: https://doi.org/10.24200/amecj.v2.i01.43
}

to food products and pharmaceutical formulas to correct possible dietary deficiencies [3]. Therefore, reliable analytical methods for the determination of Trp are of great interest.

A variety of analytical methods have been described for the determination of Trp, including high performance liquid chromatography (HPLC) [4], capillary electrophoresis [5], electroanalytical methods [6], spectrophotometry and spectrofluorimetry $[7,8]$. Compares with the Chromatographic methods, spectrofluorimetric determination is a simple, fast and inexpensive method. However, the direct determination of Trp at low concentrations by spectrofluorimetry 
is difficult because of insufficient sensitivity of this technique as well as the matrix interferences occurring in real samples, and an initial sample pretreatment, such as preconcentration of the analyte, is often necessary $[9,10]$.

Solid phase extraction (SPE) is a routine extraction method for preconcentration of organic and inorganic analytes. This technique reduces solvent usage and exposure, disposal costs, and extraction time. Various adsorbents, such as octadecyl functional groups bonded on silica gel, C18 [11], silica gel [12], chelating adsorbents [13], Amberlite $\mathrm{XAD}$ resins $[14,15]$, activated carbon [16] and other sorbents [17] have been used for adsorption of analytes in SPE methods.

Multi-walled carbon nanotubes (MWCNTs) have received great attention due to their exceptional electronic, mechanical, thermal, chemical properties and significant potential applications in many fields [18]. Owing to their large surface area and high reactivity, MWCNTs based adsorbents have been used for solid phase extraction and preconcentration of organic compounds and metal ions $[19,20]$. Compared with traditional SPE sorbents, MWCNTs offer a significantly higher surface area-to-volume ratio and a short diffusion route, resulting in high extraction capacity, low extraction time and high extraction efficiencies [21].

In this paper, a magnetic solid phase extraction method based on multi-walled carbon nanotubes is developed for the extraction and preconcentration of L-tryptophan( $\alpha$-amino acid), prior to its spectrofluorometric determination.

\section{Experimental}

\subsection{Reagents}

All reagents used were of analytical grade and were used as supplied. $\mathrm{NaOH}$, ammonia solution, were purchased from Merck (Germany). MWCNTs (purity $>95 \%$ ) were obtained from Sigma-Aldrich. Standard stock solution $\left(1000 \mu \mathrm{g} \mathrm{mL}^{-1}\right)$ of L-tryptophan was prepared by dissolving the pure solid (Sigma-Aldrich) in deionized water. Working solutions were prepared daily by adequate dilution with deionized water.

\subsection{Instrumentation}

The fluorescence measurements were performed using a Perkin-Elmer LS50 spectrofluorometer, equipped with a xenon discharge lamp. A Metrohm model 744 digital $\mathrm{pH}$ meter, equipped with a combined glass-calomel electrode, was employed for the $\mathrm{pH}$ adjustments.

\section{3. solid-phase extraction procedure}

A $40 \mathrm{~mL}$ sample or standard solution containing L-Trp (pH 6) was transferred in a polypropylene centrifuge tube. Then $10 \mathrm{mg}$ of MWCNTs was added into the sample solution. The mixture was shaken for $5 \mathrm{~min}$. The solution was centrifuged for $5 \mathrm{~min}$ at 5,000 rpm, and the aqueous phase was removed. The preconcentrated target analyte was eluted using $1.0 \mathrm{~mL}$ of a $2 \mathrm{~mol} \mathrm{~L}^{-1}$ solution of $\mathrm{NaOH}$. The $\mathrm{pH}$ of this solution was adjusted at 10 by addition of $2 \mathrm{~mol} \mathrm{~L}^{-1}$ hydrochloric acid and then solution made up to $2.0 \mathrm{ml}$ with deionized water. Finally, the concentration of L-tryptophan was determined spectrofluorometrically at $\lambda_{\mathrm{em}}=360$ $\mathrm{nm}$ after excitation at $274 \mathrm{~nm}$.

\subsection{Sample preparation}

For digestion of wheat and barley samples, $20.0 \mathrm{~mL}$ $\mathrm{KOH}(10 \% \mathrm{~m} / \mathrm{v})$ were added to $0.20 \mathrm{~g}$ of sample powder in a $100.0 \mathrm{~mL}$ conical flask to hydrolyze in an oven at $40{ }^{\circ} \mathrm{C}$ for $16-18 \mathrm{~h}$. Then, the mixture was filtered through a filter paper and adjusted to $\mathrm{pH} 6$ by the addition of $6 \mathrm{M}$ HCI. Finally the solution made up to $50.0 \mathrm{ml}$ with deionized water.

\section{Results and discussion}

\subsection{Optimization of extraction conditions}

\subsubsection{Effect of $\mathrm{pH}$}

The effect of $\mathrm{pH}$ on the extraction of L-Trp was studied in the range of 3.0-11.0 using nitric acid or ammonium acetate. The resulting percent recovery$\mathrm{pH}$ plot is shown in Fig. 1, which indicates that sorption is maximum and quantitative in the $\mathrm{pH}$ range 3.0-9.0. Therefore, $\mathrm{pH} 6.0$ was selected for further study. 


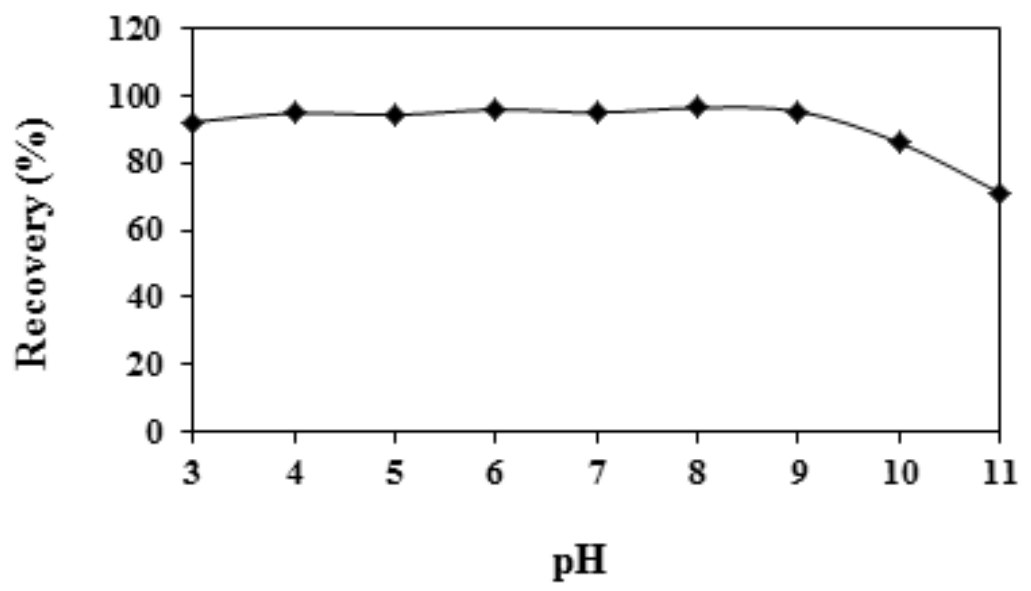

Fig. 1. Effect of $\mathrm{pH}$ on the extraction efficiency of L-Trp. Conditions: sample volume, $40 \mathrm{~mL}$; MWCNTs amount, 10

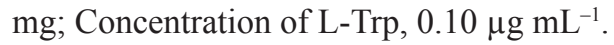

\subsubsection{Effect of the sorbent amount}

In comparison with the traditional sorbents, MWCNTs offer a significantly higher surface areato-volume ratio. Therefore, satisfactory results can be achieved with fewer amounts of MWCNTs. In order to study the effect of the sorbent, 2 to $20 \mathrm{mg}$ of MWCNTs was added to $40 \mathrm{~mL}$ of the sample solution (Fig. 2). The obtained results showed that by increasing the sorbent amounts from 2 up to 10 $\mathrm{mg}$ due to increasing accessible sites, extraction recovery increased and after that remained constant. A $10 \mathrm{mg}$ of the MWCNTs was selected for subsequent experiments.

\subsubsection{Effect of eluent type}

In order to find the best eluent, different eluting solutions such as $\mathrm{HCl}, \mathrm{HNO}_{3}$, acetic acid, $\mathrm{NaOH}$, were tested. Obtained results showed that among the tested eluent, $\mathrm{NaOH}$ was found to be the superior solvent in comparison with other solvents for desorption of analytes from surface of the sorbent. Therefore, $\mathrm{NaOH}$ solution was selected and used as an eluent. The effect of $\mathrm{NaOH}$ concentration on the recovery of the adsorbed L-Trp was examined in the range of 0.1 to $5 \mathrm{~mol} \mathrm{~L}^{-1}$ (Fig. 3). Based on the obtained results, $2.0 \mathrm{~mol} \mathrm{~L}^{-1} \mathrm{NaOH}$ was sufficient for complete elution of the adsorbed Trp on the sorbent surface. To achieve the highest recovery

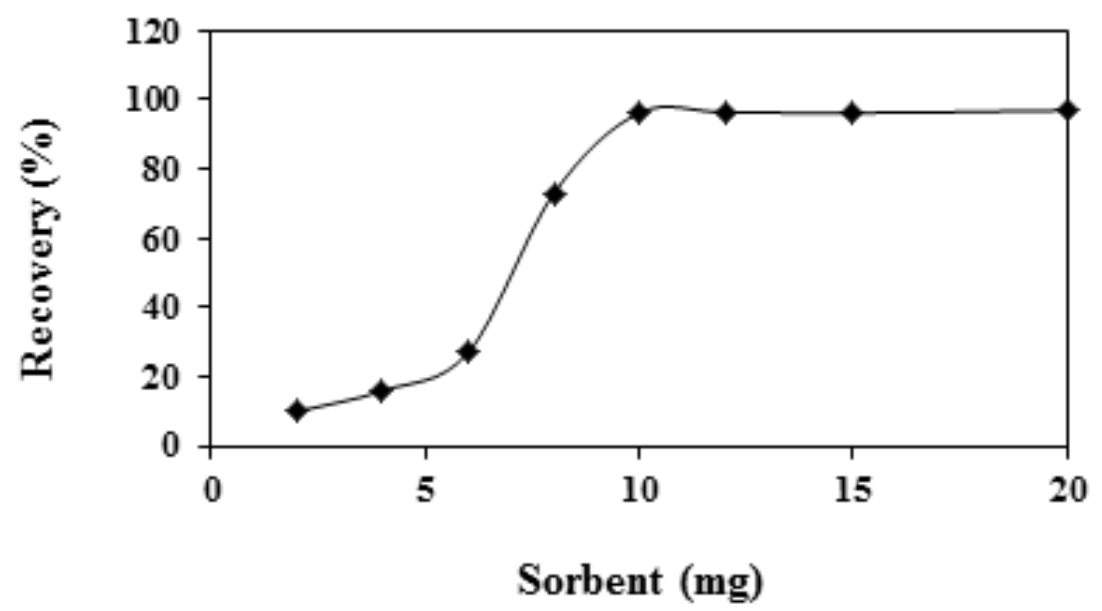

Fig. 2. Effect of the MWCNTs amount on the recovery of L-Trp. Conditions: pH, 6, sample volume, $40 \mathrm{~mL}$; Concentration of L-Trp: $10 \mu \mathrm{g} \mathrm{mL}^{-1}$. 


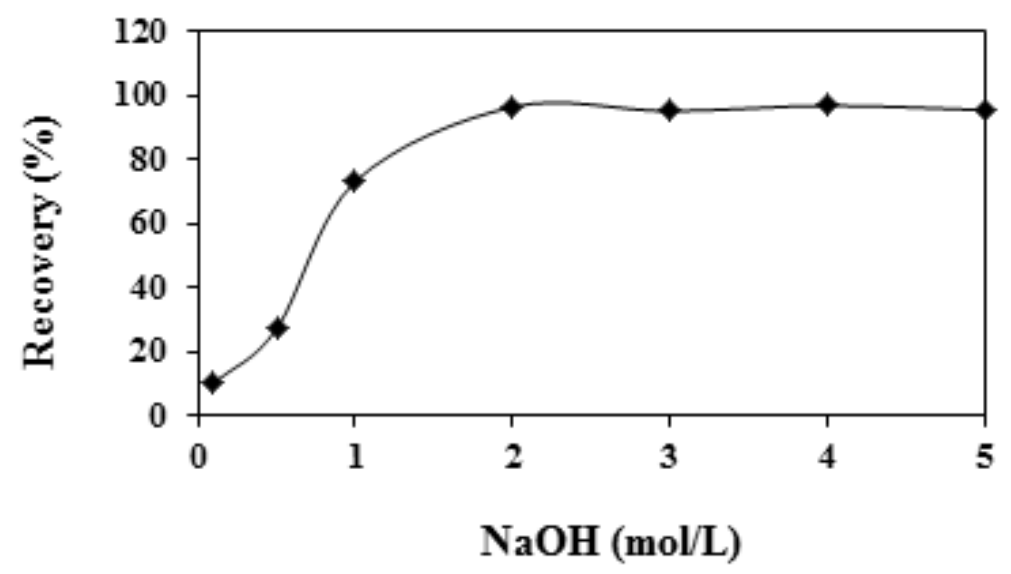

Fig. 3. Effect of $\mathrm{NaOH}$ concentration on the extraction efficiency of L-Trp. Conditions: $\mathrm{pH}, 6$, sample volume, $40 \mathrm{~mL}$; MWCNTs-Fe ${ }_{3} \mathrm{O}_{4}$ amount, $10 \mathrm{mg}$; Concentration of L-Trp, $0.10 \mu \mathrm{g} \mathrm{mL} \mathrm{mL}^{-1}$.

of the adsorbed L-Trp, the effect of the volume of the eluent was also tested. The minimum volume of $\mathrm{NaOH}$ required for quantitative elution of the retained analyte was $1.0 \mathrm{~mL}$.

\subsubsection{Effect of extraction time}

The effect of extraction time on the extraction of L-Trp was studied in the range of 1-15 $\mathrm{min}$. The experimental results indicated that there was no significant effect on the extraction efficiency when the extraction time increased from 5 to $15 \mathrm{~min}$. Based on the above considerations, 5 min was selected for further studies.

\subsubsection{Sorption capacity}

In order to determine the maximum capacity for L-Trp, $20 \mathrm{mg}$ of the adsorbent was added to 40 $\mathrm{mL}$ of an aqueous solution containing $20 \mathrm{mg} \mathrm{L}^{-1}$ L-Trp and shaken it for 30 min under optimized conditions. After decantation of the sorbent, the concentration of retained L-Trp in the supernatant solution was determined. The maximum capacity was found to be $36.3 \mathrm{mg} \mathrm{g}^{-1}$ for L-Trp.

\subsection{Analytical figures of merit}

Table 1 summarizes the analytical characteristics of the proposed method, including linear range, limit of detection, reproducibility, and enhancement factor. In the optimum conditions, a calibration graph was constructed by preconcentrating a series of the solutions according to the procedure under experimental. The linear regression equation for the calibration graph for the concentration range of $0.04-3.40 \mu \mathrm{g} \mathrm{mL} \mathrm{m}^{-1}$ was $I=92.69 \mathrm{C}+74.43$ $\left(\mathrm{r}^{2}=0.9984, \mathrm{n}=8\right)$, where $I$ is the fluorescence intensity and $\mathrm{C}$ is $\operatorname{Trp}$ concentration in the sample solution in $\mu \mathrm{g} \mathrm{mL}^{-1}$.

The limit of detection (LOD) of the proposed method for the determination of Trp was studied under the optimal experimental conditions. The LOD, defined as three times the standard deviation of 10 measurements of the blank solution divided by the slope of the calibration curve, was $8.9 \mathrm{ng}$ $\mathrm{mL}^{-1}$. The reproducibility of the proposed method for extraction and determination of $0.10 \mu \mathrm{g} \mathrm{mL}^{-1}$ $\operatorname{Trp}(\mathrm{n}=10)$ was also studied. The relative standard deviation (R.S.D.) of these determinations was 2.6 $\%$.

\subsection{Application}

The proposed method was applied to the determination of L-Trp in wheat and barley samples

Table 1. Analytical parameters of the proposed method.

\begin{tabular}{ll}
\hline Parameter & Analytical feature \\
\hline Linear range $\left(\mu \mathrm{g} \mathrm{mL}^{-1}\right)$ & $0.04-3.40$ \\
Calibration equation & $I=92.69 \mathrm{C}+74.43$ \\
$\mathrm{r}^{2}$ & 0.9984 \\
LOD $\left(\mathrm{ng} \mathrm{mL}^{-1}\right)$ & 8.9 \\
R.S.D. $\%(\mathrm{n}=10)$ & 2.6 \\
\hline
\end{tabular}


Table 2. Determination of tryptophan in food samples.

\begin{tabular}{lcc}
\cline { 2 - 3 } Sample & \multicolumn{2}{c}{ Tryptophan $(\mathrm{mg} / \mathrm{g})$} \\
\cline { 2 - 3 } & Proposed method & HPLC \\
\cline { 2 - 3 } Wheat & $1.54 \pm 0.04$ & 1.63 \\
Barley & $1.26 \pm 0.03$ & 1.14 \\
\hline
\end{tabular}

and the obtained results by proposed method were compared with HPLC method. The results obtained are shown in Tables 2. The results demonstrated that the proposed method was suitable for the determination of L-Trp in real samples.

\section{Conclusions}

A simple and fast SPE method based on MWCNTs was developed for the preconcentration and spectrofluorimetric determination of L-Trp. The use of NPs endued the SPE method with high extraction capacity and preconcentration factors. Also using spectrofluorimetry as a detection system exhibits a low primary and operational cost in comparison with other methods such as HPLC. The method can be successfully applied to the separation and determination of tryptophan in real samples.

\section{References}

[1] W. Amelung, X. Zhang, K.W. Flach, Amino acids in grassland soils: climatic effects on concentrations and chirality, Geoderma, 130 (2006) 207-217.

[2] M. Ikeda, Amino Acid Production Processes. Adv. Biochem. Eng. Biotechnol. 79 (2002) 1-35.

[3] C. Delgado-Andrade, J.A. Rufián-Hanares, S. Jiménez-Pérez, F.J. Morales, Tryptophan determination in milk-based ingredients and dried sport supplements by liquid chromatography with fluorescence detection, Food Chem., 98 (2006) 580-585.

[4] D.I. Sanchez-Machado, B. Chavira-Willys, J. Lopez-Cervantes, High-performance liquid chromatography with fluorescence detection for quantitation of tryptophan and tyrosine in a shrimp waste protein concentrate, J Chromatogr., 863 (2008) 88-93.

[5] Takagai Y, Igarashi S. Determination of ppb levels of tryptophan derivatives by capillary electrophoresis with homogeneous liquid-liquid extraction and sweeping method, Chem. Pharm. Bull., 51 (2003) 373-377.

[6] A.R. Fiorucci, E.T.G. Cavalheiro, The use of carbon paste electrode in the direct voltammetric determination of tryptophan in pharmaceutical formulations, J. Pharm. Biomed. Anal., 28 (2002) 909-915.

[7] J. Ren, M. Zhao, J. Wang, C. Cui, B. Yang, Spectrophotometric method for determination of tryptophan in protein hydrolysates, Food Technol. Biotechnol., 45 (2007) 360-366.

[8] A.M. Othmana, S. Lib, R.M. Leblancb, Enhancing selectivity in spectrofluorimetric determination of tryptophan by using graphene oxide nanosheets, Anal. Chim. Acta, 787 (2013) 226-232.

[9] H. Abdolmohammad-Zadeh, S.M. HammamiOskooyi, Solid-phase extraction of 1-tryptophan from food samples utilizing a layered double hydroxide nano-sorbent prior to its determination by spectrofluorometry, J. Iran. Chem. SOC., 12 (2015) 1115-1122.

[10] X. Zhu, Y. Gu, Modified nano- $\mathrm{TiO}_{2}$ coupled with fluorescence spectroscopy for the separation/ analysis of L-tryptophan, Anal. Biochem., 401 (2010) 260-265.

[11] E. Zolfonoun, A. Rouhollahi, A. Semnani, Solidphase extraction and determination of ultra trace amounts of lead, mercury and cadmium in water samples using octadecyl silica membrane disks modified with 5,50-dithiobis(2-nitrobenzoic acid) and atomic absorption spectrometry, Int. J. Environ. Anal. Chem., 88 (2008) 327-336.

[12] N. Wanga, X. Liang, Q. Li, Y. Liao, S. Shao, Nitrosubstituted 3,3'-bis(indolyl)methane-modified silica gel as a sorbent for solid-phase extraction of flavonoids, RSC Adv., 5 (2015) 15500-15506.

[13] E. Yavuz, S. Tokalığlu, H. Erkılıç, C. Soykan, Novel chelating resin for solid-phase extraction of metals in certified reference materials and waters, Anal. Lett., 50 (2017) 364-378.

[14] J.B. Ghasemi, E. Zolfonoun, Simultaneous spectrophotometric determination of trace amounts of uranium, thorium, and zirconium using the partial least squares method after their preconcentration by $\alpha$-benzoin oxime modified Amberlite XAD-2000 resin, Talanta, 80 (2010) 1191-1197.

[15] K. Saberyan, E. Zolfonoun, M. Shamsipur, M. Salavati-Niasari, Separation and preconcentration 
of trace gallium and indium by amberlite XAD-

7 resin impregnated with a new hexadentates naphthol-derivative schiff base, Sep. Sci. Technol., 44 (2009) 1851-1868.

[16] Z.A. Alothman, E. Yilmaz, M. Habila, M. Soylak, Solid phase extraction of metal ions in environmental samples on 1-(2-pyridylazo)-2naphthol impregnated activated carbon cloth, Ecotoxicol. Environ. Saf., 112 (2015) 74-79.

[17] H. Ebrahimzadeh, M. Behbahani, A novel lead imprinted polymer as the selective solid phase for extraction and trace detection of lead ions by flame atomic absorption spectrophotometry: Synthesis, characterization and analytical application, Arab. J. Chem., 12 (2017) 2499-2508.

[18] R.H. Baughman, A.A. Zakhidov, W.A. deHeer, Carbon nanotubes-the route toward applications,
Science, 297 (2002) 787-792.

[19] D. Pardasani, P.K. Kanaujia, A.K. Purohit, A.R. Shrivastava, D.K. Dubey, Magnetic multi-walled carbon nanotubes assisted dispersive solid phase extraction of nerve agents and their markers from muddy water, Talanta, 86 (2011) 248-55.

[20] E. Stanisz, M. Krawczyk, H. Matusiewicz, Solid-phase extraction with multiwalled carbon nanotubes prior to photochemical generation of cadmium coupled to high-resolution continuum source atomic absorption spectrometry, J. Anal. At. Spectrom., 29 (2014) 2388-2397.

[21] D. Shao, C. Chen, X. Wang, Application of polyaniline and multiwalled carbon nanotube magnetic composites for removal of $\mathrm{Pb}(\mathrm{II})$, Chem. Eng. J., 185 (2012) 144-150. 